\title{
Thermal imaging compared to dermoscopy in evaluation of skin melanocytic lesions
}

Danuta Mikulska, Romuald Maleszka

Department of Skin and Venereal Diseases, Pomeranian Medical University, Szczecin, Poland

\section{The aim of the study:}

An attempt of comparative analysis of dermoscopic, thermographic and histopathological pictures of the melanocytic nevi of the skin.

\section{Material and methods}

The study enrolled 245 patients with 735 melanocytic nevi and 12 patients with malignant melanoma. All melanocytic lesions were studied with application of Heine delta 10 dermatoscope in order to evaluate the TDS (total dermatoscopy score - according to Stolz) and with application of ThermaCAMTM S.C. 500 thermographic camera in order to measure the maximal (Tmax), minimal (Tmin), and average temperatures and calculate the difference between maximal and minimal temperatures shown as $\Delta T\left({ }^{\circ} \mathrm{C}\right)=T$ max-Tmin. Histopathological evaluation was performed in 127 melanocytic nevi and 12 malignant melanomas. Statistical analysis was performed using Statistica 6.0 software. The comparative analysis of mean values between the groups was performed with application of t-Student test, and Pearson ( $r$ ) coefficient was applied to test the linear correlation between the variables.

\section{Results}

In the dermoscopic studies of 735 melanocytic nevi the mean TDS score was $4,03+/-0,68$. The mean TDS score for 554 melanocytic nevi was 3,89+/-0,3, for 181 atypical melanocytic nevi $-5,19+/-0,21$, and for 12 malignant melanomas- $5,96+/-0,25$. The mean values of maximal temperatures for the whole group of 735 melanocytic nevi were $33,5+/-0,3^{\circ} \mathrm{C}$. These results did not differ significantly from the control group- $33,2+/-0,6^{\circ} \mathrm{C}$ $(p>0,05)$. The mean values of maximal temperatures for the 554 benign melanocytic nevi were $33,1+/-0,7$ ( $>>0,05)$, for 181 atypical melanocytic nevi- 33,7+/-0,4 $(p<0.05)$, and for 12 malignant melanomas- $34,1+/-0,8$ $(\mathrm{p}<0,01)$. The mean values of the average temperatures for the 735 melanocytic nevi were $31,9+/-/ 1,0{ }^{\circ} \mathrm{C}$. These results did not differ statistically significantly when compared to the control group $-31,8+/-0,9(p>0,05)$. The mean values of the average temperatures for 554 benign melanocytic nevi were $31,8+/-1,0 \quad(p>0,05)$, for 181 atypical melanocytic nevi- 32,0+/-1,1 ( $p>0,05)$, and for 12 malignant melanomas- 33,0+/-0,9 ( $<<0,01)$. The mean values of $\Delta T\left({ }^{\circ} \mathrm{C}\right)$ coefficient in the whole group of melanocytic nevi were $1,2+/-0,2$. The data did not differ significantly from the control group $-1,1+/-0,2$ ( $>>0,05)$. The mean values of $\Delta T\left({ }^{\circ} \mathrm{C}\right)$ coefficient for 554 benign melanocytic nevi were 1,1+/- $0,3(p>0,05)$, for 181 atypical melanocytic nevi- 1,39+/-28 $(p<0.001)$, and for 12 malignant melanomas- $1,6+/-0,4$ ( $p<0,001)$. Positive correlations were found between the results of dermoscopic, thermographic and histopathological examination of the melanocytic nevi.

\section{Conclusions}

Thermovision may be an adjuvant study method supporting the dermoscopic evaluation in the diagnostics of atypical (suspicious) melanocytic nevi and other skin lesions suspected for malignancy. 2/ The result of thermographic examination and the calculated $\Delta T\left({ }^{\circ} \mathrm{C}\right)$ coefficient correlate positively with the result of the dermoscopic evaluation and TDS score. 3/ Surgery or close follow-up to recognize malignant metaplasia may be applied in cases of the melanocytic nevi with $\Delta \mathrm{T}\left({ }^{\circ} \mathrm{C}\right)$ coefficient $>1,4 \mathrm{OC}$ and TDS score $>4.75$. 4/The average temperatures of the common and atypical melanocytic nevi do not reveal any significant difference when compared to the average temperatures of skin without the pigmented lesions. Acknowledgements: This research was supported by State Committee for Scientific Research - KBN (Grant No 3T11E04526). 
http://dx.doi.org/10.21611/qirt.2008.03_05_17 